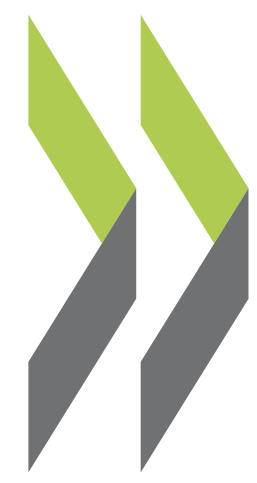

PEB Exchange, Programme on Educational Building 1999/02

\title{
Educational Building and Decentralisation \\ in Mexico
}

OECD

https://dx.doi.org/10.1787/468031431237 


\section{EDUCATIONAL BUILDING AND DECENTRALISATIO N IN MEXICO}

Mexico at a G lance
Total area: $1973000 \mathrm{~km}^{21}$
Population (in 1996): $96582000^{1}$
Population under 15 years old (in 1995): $36.2 \% 1$
Children between 6 and 14 years old attending school:
93.6\% $\%^{2}$
Children having at least one year of preschool
education:
$\quad$ - before decentralisation: $74 \%^{2}$
$\quad$ - after decentralisation: $90 \%^{2}$
Children having completed elementary school:
$\quad$ - before decentralisation: $72 \%{ }^{2}$
$\quad-$ after decentralisation: $85 \%{ }^{2}$
The Mexican Educational System
Preschool - optional: 3 years
Elementary school - compulsory: 6 years
Junior secondary school - compulsory: 3 years
Preparatory school (upper secondary school) -
optional: 3 years

\section{Historical background}

The Administrative Board of the Federal School Construction Programme (CAPFCE) has been in existence for 54 years, but it was only in 1977 that initial efforts were made to transfer responsibility for educational building to the administrations of the 32 states of Mexico. In 1985, legislation wasintroduced to change the CAPFCE's structure, powers and functions with a view to bringing them in line with the objectives of decentralisation and modernisation of the country. Initiatives were implemented in order to promote the participation of state governments, municipal authorities and communities in educational building, resource management and building maintenance activities.

The key points of the agreement on the decentralisation of the CAPFCE, which defined the decentral isation strategy at the beginning of 1996, are as follows:

- Planning of work: the states are responsible for the planning of all primary education infrastructure.
- Construction and management of buildings: state and municipal authorities are now responsible for managing educational buildings.

- Allocation of funding: a funding allocation procedure that takes into account a number of variables, such as the wealth or growth rate of the local population, has been drawn up.

- Secondary education: the federal government and states, which now have joint responsibility for the planning of secondary school facilities, will examine decentralisation in this field, and in particular the process by which schools will increasingly assume responsibility for developing their infrastructure.

- Restructuring of the CAPFCE: because of the substantial differences in the technical and administrative capacity of the various states and municipalities, the CAPFCE will temporarily act as a fund for financing educational infrastructure while at the same time retaining certain supervisory functions.

\section{The programme for decentralising the CAPFCE}

During the first stage, which took place in 1996, the broad lines of the above agreement were laid down, formally launching the decentralisation programme at the primary education level. In 1997, during the second stage, the Administrative Board consolidated the process at the primary level, extended it to the secondary and university levels and launched initiatives to create educational building agencies in states.

The programme'simplementation reveal ed a number of shortcomings in the organisational structure of the governments of the various states. Technical and administrative deficiencies have slowed down the implementation of investment programmes, and a lack of institutional co-ordination and difficulties in defining procedures for implementing the plan have prompted some states to create their own educational building agency.

\section{Creation of state educational building agencies}

In line with the decentralisation programme, a major effort was made in 1997 to set up state educational building agencies, which were seen

1. OECD (1998), "OECD in Figures", supplement to The O ECD O bserver, No. 212, June/July 1998, Paris.

2. $4^{\text {th }}$ Report to the G overnment, September 1998 (summary of President Zedillo's mandate for the past presidential year). 


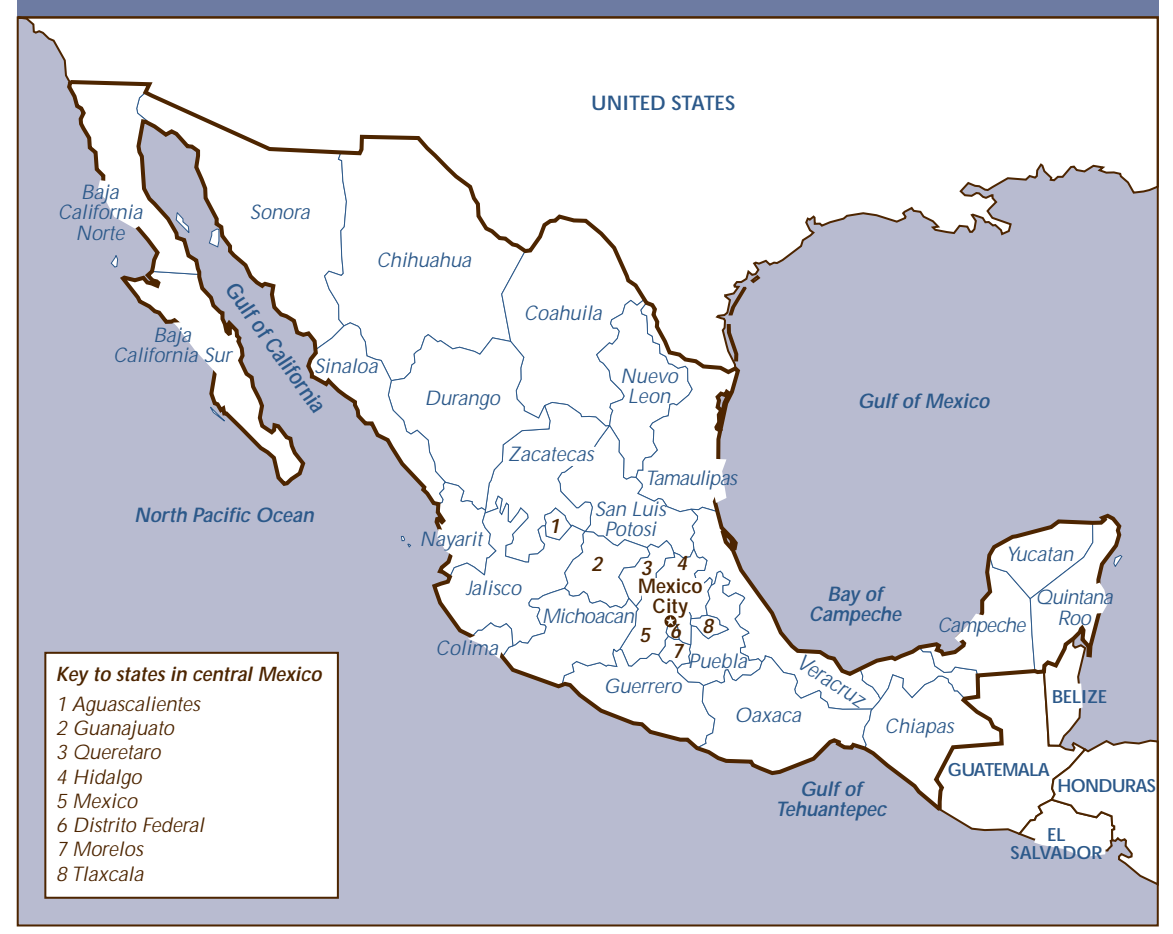

functions have been decentralised, the CAPFCE will have the new responsibility of setting technical standards for educational infrastructure nation-wide. The CAPFCE will be responsible for defining and approving architectural projects involving the design and use of space in educational facilities, and for establishing methods and procedures for certifying diplomas in accordance with the applicable standards.

The decentralisation will be implemented as follows:

- By the end of 1998, the states were to have established local agencies responsible for the construction, renovation and maintenance of their schools.

as the institutional mechanism that would make it possible to decentralise educational infrastructure construction completely.

In 1998, the CAPFCE managed a budget of 615 million pesos for the construction, equipping and maintenance of educational facilities. The Administrative Board considers that it is essential for each entity which has established a local educational building agency to be able to receive its funding allocation directly from this agency, now that the CAPFCE's human, physical and financial resources are being transferred to local entities under the relevant legal agreements.

The CAPFCE is being transformed so as to ensure a broader and more equitable distribution of responsibilities and greater participation of executive authorities, municipalities, local communities and society at large. This change is taking shape through consultations and agreements between the various sectors and the nation's political and social actors.

\section{The CAPFCE's new role}

The CAPFCE is now a body that sets standards, exercises technical supervision and provides financial assistance. A 1985 decree laid down that "the Board shall define technical standards for the construction, equipping and authorisation of buildings and school facilities". Once its original
- The CAPFCE will transfer the physical infrastructure and resources necessary to enable the new agencies to operate.

- Municipalities and local communities will be increasingly involved in all aspects of educational infrastructure.

As for the CAPFCE, it will now have the following responsibilities:

- To promote scientific and technological improvements in the construction of educational facilities.

- To establish the most adequate technical standards for the construction, equipping and renovation of the country's educational infrastructure.

- To supervisethe progress and quality of the work being done in decentralised entities.

- To provide financial support to these entitiesfor the development of their respective programmes.

- To provide training in all areas mentioned above. 